\title{
EFICIÊNCIA DO HERBICIDA LACTOFEN NO CONTROLE DE Euphorbia heterophylla RESISTENTE AOS HERBICIDAS INIBIDORES DA ENZIMA ACETOLACTATO SINTASE (ALS)
}

\author{
André Luiz Melhorança ${ }^{1}$ e Francisco de Assis R. Pereira ${ }^{2}$
}

' Embrapa Agropecuária Oeste. Caixa Postal 661. Dourados, MS 79804-970. e-mail: andré@ cpao.embrapa.br

${ }^{2}$ Empaer. Caixa Postal 472. Campo Grande, MS 79031-902

\begin{abstract}
RESUMO
A ocorrência de plantas daninhas resistentes é um processo de seleção de biótipos, com características genéticas mutantes, que suportam aplicações de certo herbicida ao qual a maioria da população é suscetível. Os herbicidas imazethapyr chlorimuron-ethyl e oxysulfuron apresentam o mesmo mecanismo de ação, ou seja, são inibidores da enzima acetolactato sintase (ALS) responsável pela síntese de três aminoácidos essenciais: valina, leucina e isoleucina. Estes herbicidas são recomendados e utilizados em larga escala no controle de Euphorbia heterophylla. Entretanto, em diversas regiões do Centro Oeste do Brasil foram identificados biótipos de E. heterophylla com resistência a esses herbicidas. Este trabalho foi conduzido em campo com o objetivo de avaliar a eficiência do herbicida lactofen aplicado isolado e em mistura com imazethapyr, chlorimuron-ethyl e oxasulfuron e flumiclorac no controle de E. heterophylla, que apresenta resistência aos herbicidas inibidores da ALS. Os resultados evidenciaram que lactofen aplicado de forma sequencial $(60+60 \mathrm{~g} / \mathrm{ha})$ foi eficiente no controle de E. heterophylla. As misturas de lactofen com imazethapyr, chlorimuron-ethyl e oxasulfuron mostraram boa eficiência de controle, demonstrando que a mistura de herbicidas com mecanismos de ação diferente é uma boa estratégia para o controle de biótipo de E. heterophylla com resistência aos herbicidas inibidores de ALS. A mistura de lactofen com flumiclorac-pentil apresentou um bom controle de E. heterophylla. Os herbicidas e as misturas nas doses testadas foram seletivos para a cultura da soja.
\end{abstract}

Palavras-chave: controle químico, soja, planta daninha.

\section{ABSTRACT \\ Efficiency of lactofen in controlling Euphorbia heterophylla resistant to herbicides inhibitors of the enzyme acetolactate synthetase (ALS)}

The occurrence of resistant weeds is a process of biotype selection, with mutant genetic traits, which support applications of certam herbicides to which most of the population are susceptible. Imazethapyr, chlorimuron-ethyl, and oxasulfuron herbicides have the same mode of action; they are inhibitors of the acectolactate synthetase enzyme (ALS), which is responsible for the synthesis of three essential aminoacids: valine, leucine, and isoleucine. These herbicides are widely recommended and used for controlling Euphorbia heterophylla. However, biotypes of E. heterophylla which are resistant to those herbicides were identified in Central Western Brazil. This work was carried out with the objective of evaluating the efficiency of lactofen, applied singly and in mixture with imazethapyr, chlorimuron-ethyl, and oxasulfuron for the control of $E$. heterophylla biotypes which are resistant to ALS inhibitors. The results showed that sequential application of lactofen at $60+60 \mathrm{~g} / \mathrm{ha}$ was efficient in controlling $E$. heterophylla. Lactofen mixtures with imazethapyr, chlorimuron-ethyl, and oxasulfuron showed good efficiency, thus demonstrating that mixing herbicides of different action mechanisms is a good strategy for controlling E heterophylla biotypes which are resistant to ALS inhibitors. Lactofen mixture with flumiclorac-pentil showed good control of $E$. heterophylla. The evaluated herbicides and mixture rates were not harmful to soybean plants.

Key words: chemical control, soybean, weed. 


\section{INTRODUÇÃO}

Os herbicidas controlam as plantas daninhas interferindo em processos metabólicos e fisiológicos vitais para essas plantas. Eles podem ser classificados de diferentes formas dependendo de seu mecanismo de ação. Geralmente, inibem a atividade de uma enzima/proteína na célula e, como conseqüência, desencadeiam uma série de eventos que matam ou inibem o desenvolvimento da célula e do organismo.

Uma das evidências mais fortes de que um herbicida inibe uma determinada enzima é o crescimento de populações de indivíduos com enzima/proteína mutante, conferindo resistência aos herbicidas (Vidal, 1997).

A variabilidade genética é uma característica inerente aos seres vivos, que permite a evolução e adaptação das espécies aos novos ambientes. Numa população de indivíduos com cruzamento não controlado é possível encontrar variabilidade fenológica, fisiológica e bioquímica. Os indivíduos mutantes ocorrem naturalmente nas populações com freqüência reduzida $\left(10^{-19}\right.$ até $\left.10^{-6}\right)$. A quantidade de indivíduos destes biótipos somente irá aumentar quando se utilizar, repetidamente, herbicidas com o mesmo mecanismo de ação (Mathews e Van Holde, 1990).

A ocorrência de plantas daninhas resistentes é um processo de seleção de biótipos, com características genéticas mutantes, que suportam aplicações de certo herbicida. Portanto, a resistência que uma planta daninha apresenta é uma característica genética, que a faz sobreviver a um herbicida ao qual a maioria da população é suscetível (Gazziero et al., 1998).

Os herbicidas imazethapyr, do grupo químico das imidazolinonas, chlorimuron-ethyl e oxasulfuron, do grupo químico das sulfoniluréias (Rodrigues e Almeida, 1998) apresentam o mesmo mecanismo de ação, ou seja, são inibidores irreversíveis da enzima acetolactato sintase (ALS) responsável por catalisar a síntese de três aminoácidos essenciais: valina, leucina e isoleucina (Vidal, 1997). Estes herbicidas são recomendados e utilizados em larga escala no controle de E. heterophylla. Entretanto, em diversas regiões do Centro-Oeste do Brasil foram identificados biótipos de E. heterophylla com resistência a esses herbicidas inibidores de ALS.

Uma das estratégias para evitar a resistência de plantas daninhas aos herbicidas, é a rotação de culturas e de herbicidas com mecanismo de ação diferente ou mistura de produtos com mecanismo de ação diferente, como inibidores de ALS com inibidores de protox, tais como lactofen que pertence ao grupo químico dos difeniléteres e flumiclorac-pentil do grupo químico das ftalimidas, que são inibidores da enzima protox, que cataliza a síntese de porfirinas ou tetrapiroles (Vidal, 1997).

O objetivo do presente trabalho foi avaliar a eficiência do herbicida lactofen aplicado isolado e em mistura com imazethapyr, chlorimuron-ethyl, oxasulfuron e flumiclorac-pentil no controle de E. heterophylla, que apresenta resistência aos principais herbicidas inibidores de acetolactato sintase (ALS).

\section{MATERIAL E MÉTODOS}

O experimento foi instalado em campo na área de produção da Fazenda Basto, município de Caarapó-MS, de acordo com normas preconizadas pela Sociedade Brasileira da Ciências das Plantas Daninhas (1995), durante a safra de 1998/99. A soja foi semeada em 15/11/98, com emergência em 19/11/98, e os tratamentos foram aplicados em 05/ 12/98 e 12/12/98. A cultivar utilizada foi a FT Jatobá com espaçamento de $45 \mathrm{~cm}$ entre linhas e densidade de 25 plantas por metro. Foram realizadas as práticas culturais recomendadas para a região (Embrapa, 1996).

Os tratamentos testados, com suas respectivas concentrações, doses de produto comercial e do ingrediente ativo por hectare são apresentados na Tabela 1 .

Os tratamentos foram aplicados com auxílio de um pulverizador costal propelido a $\mathrm{CO}_{2}$, equipado com barra de $1,5 \mathrm{~m}$ contendo quatro bicos leque 110.02 , trabalhando a uma pressão de $2,11 \mathrm{~kg} / \mathrm{cm}^{2}$, proporcionando uma vazão de 200 1/ha. As condições ambientais no momento da aplicação eram de tempo parcialmente nublado, temperatura do ar de $23^{\circ} \mathrm{C}$, umidade relativa de $71 \%$ e velocidade do vento de 1 a $3 \mathrm{~km} / \mathrm{h}$.

O experimento foi delineado em blocos ao acaso com nove tratamentos e quatro repetições. As parcelas apresentaram uma área total de $16 \mathrm{~m}^{2}(2 \mathrm{~m} \times 8 \mathrm{~m})$ e área útil de $6 \mathrm{~m}^{2}(1$ $\mathrm{m} \times 6 \mathrm{~m})$. Os dados coletados foram submetidos à análise de variância e ao teste F. Para comparação de médias utilizouse o teste de Tukey a 5\% de probabilidade (Pimentel Gomes, 1984 e 1985).

Realizaram-se avaliações de eficiência e seletividade aos 7, 14 e 30 dias após tratamento (DAT) e na pré-colheita, empregando-se, para seletividade, o método de avaliação visual através de uma escala de 0 a 100 , onde $0=$ nenhuma injúria na planta e $100=$ morte total da planta.

A área experimental apresentava alta densidade (24 plantas $/ \mathrm{m}^{2}$ ) de E. heterophylla, identificada de acordo com Lorenzi (1990), e no momento da aplicação se encontrava no estádio de duas a três folhas. 
Tabela 1. Tratamentos testados, com suas respectivas concentrações, doses de produto comercial e ingrediente ativo por hectare.

\begin{tabular}{lccc}
\hline & \multirow{2}{*}{ Tratamento } & Concentração & \multicolumn{2}{c}{ Dose } \\
\cline { 3 - 4 } & $(\mathbf{g} / \mathbf{k g}$ ou l $)$ & (ml ou g p.c./ha) & (g i.a./ha) \\
\hline Testemunha sem capina & - & - & - \\
Lactofen & 240 & 500 & 120 \\
Lactofen - lactofen & $240-240$ & $250-250$ & $60-60$ \\
Lactofen + imazethapyr & $240+100$ & $500+500$ & $120+50$ \\
Lactofen + chlorimuron & $240+250$ & $500+50$ & $120+12,5$ \\
Lactofen + oxasulfuron & $240+750$ & $500+60$ & $120+45$ \\
Lactofen + flumiclorac & $240+100$ & $500+400$ & $120+40$ \\
Imazethapyr & 100 & 800 & 80 \\
lmazethapyr + chlorimuron & $100+250$ & $500+50$ & $50+12,5$ \\
\hline
\end{tabular}

Tabela 2. Percentagens de controle de Euphorbía heterophylla aos 7, 14 e 30 dias após aplicação dos tratamentos (DAT) e na pré-colheita (PRE). Caarapó-MS, 1998/99.

\begin{tabular}{lccccc}
\hline \multirow{2}{*}{ Tratamento } & \multirow{2}{*}{$\begin{array}{c}\text { Dose } \\
\text { (g/ha) }\end{array}$} & 7 DAT & 14 DAT & 30 DAT & PRÉ \\
\cline { 3 - 6 } & - & $0 \mathrm{c}^{1}$ & $0 \mathrm{c}^{1}$ & $0 \mathrm{~d}^{1}$ & $0 \mathrm{~d}^{1}$ \\
\hline Testemunha sem capina & 120 & $85 \mathrm{a}$ & $84 \mathrm{a}$ & $82 \mathrm{~b}$ & $80 \mathrm{~b}$ \\
Lactofen & $60-60$ & $88 \mathrm{a}$ & $87 \mathrm{a}$ & $86 \mathrm{ab}$ & $85 \mathrm{ab}$ \\
Lactofen - lactofen & $120+50$ & $85 \mathrm{a}$ & $88 \mathrm{a}$ & $98 \mathrm{a}$ & $88 \mathrm{a}$ \\
Lactofen + imazethapyr & $120+12,5$ & $85 \mathrm{a}$ & $87 \mathrm{a}$ & $88 \mathrm{ab}$ & $89 \mathrm{a}$ \\
Lactofen + chlorimuron & $120+45$ & $84 \mathrm{a}$ & $88 \mathrm{a}$ & $89 \mathrm{a}$ & $88 \mathrm{a}$ \\
Lactofen + oxasulfuron & $120+40$ & $86 \mathrm{a}$ & $85 \mathrm{a}$ & $85 \mathrm{ab}$ & $85 \mathrm{ab}$ \\
Lactofen + flumiclorac & 80 & $40 \mathrm{~b}$ & $35 \mathrm{~b}$ & $30 \mathrm{c}$ & $30 \mathrm{c}$ \\
Imazethapyr & $50+12,5$ & $45 \mathrm{~b}$ & $40 \mathrm{~b}$ & $35 \mathrm{c}$ & $30 \mathrm{c}$ \\
lmazethapyr + chlorimuron & & $269,5 * *$ & $550,8 * *$ & $544,2^{* *}$ & $749,1^{* *}$ \\
\hline F & 5,7 & 4,2 & 4,4 & 3,9 \\
CV (\%) & & 5,7 &
\end{tabular}

${ }^{1}$ Médias seguidas de mesma letra não diferem significativamente entre si, pelo teste de Tukey a 5\% de probabilidade.

\section{RESULTADOS E DISCUSSÃO}

As percentagens de controle de E. heterophylla aos 7, 14 e 30 dias após aplicação dos tratamentos (DAT) e na pré-colheita são apresentadas na Tabela 2. Verifica-se que lactofen a $120 \mathrm{~g} / \mathrm{ha}$ ou em aplicação seqüencial $(60+60 \mathrm{~g} / \mathrm{ha})$ proporcionaram bom controle, sendo significativamente superiores a imazethapyr a $80 \mathrm{~g} / \mathrm{ha}$ e imazethapyr + chlorimuronethyl $(50+12,5 \mathrm{~g} / \mathrm{ha})$, que apresentaram baixo controle dessa planta daninha, mostrando que os biótipos de E. heterophylla presentes no experimento são resistentes aos herbicidas inibidores de ALS. Este resultado, de certa forma, confirma a citação de Vidal (1997) de que foram identificados biótipos resistentes dessa planta daninha em diversas regiões do Brasil.
As misturas de lactofen com imazethapyr, chlorimuron-ethyl e oxasulfuron proporcionaram um bom controle, indicando ser a mistura de herbicidas com mecanismos de ação diferente uma boa estratégia para o controle desse biótipo de E. heterophylla, estando de acordo com Gazzieiro et al. (1998).

A aplicação seqüencial de lactofen não diferiu significativamente de lactofen em uma única aplicação, mas o lactofen em dose única obteve os menores índices entre os tratamentos que se mostraram eficientes.

A mistura de lactofen com flumiclorac-pentil mostrou um bom controle, não diferindo significativamente de lactofen aplicado isolado e em misturas, e superior a imazethapyr ou na mistura com chlorimuron-ethyl. 
Tabela 3. Percentagens de fitotoxicidade aos 7, 14 e 30 dias após aplicação dos tratamentos (DAT). Caarapó-MS, $1998 / 99$.

\begin{tabular}{lcccc}
\hline & \multirow{2}{*}{$\begin{array}{c}\text { Dose } \\
\text { Tratamento }\end{array}$} & \multicolumn{3}{c}{ Fitotoxicidade (\%) } \\
\cline { 3 - 5 } & & 7 DAT & 14 DAT & 30 DAT \\
\hline Testemunha sem capina & - & $0 \mathrm{c}^{1}$ & $0 \mathrm{~d}^{1}$ & 0 \\
Lactofen & 120 & $20 \mathrm{a}$ & $5 \mathrm{c}$ & 0 \\
Lactofen - lactofen & $60-60$ & $15 \mathrm{~b}$ & $10 \mathrm{~b}$ & 0 \\
Lactofen + imazethapyr & $120+50$ & $20 \mathrm{a}$ & $12 \mathrm{~b}$ & 0 \\
Lactofen + chlorimuron & $120+12,5$ & $18 \mathrm{a}$ & $10 \mathrm{~b}$ & 0 \\
Lactofen + oxasulfuron & $120+45$ & $20 \mathrm{a}$ & $10 \mathrm{~b}$ & 0 \\
Lactofen + flumiclorac & $120+40$ & $20 \mathrm{a}$ & $5 \mathrm{c}$ & 0 \\
Imazethapyr & 80 & $15 \mathrm{~b}$ & $10 \mathrm{~b}$ & 0 \\
lmazethapyr + chlorimuron & $50+12,5$ & $10 \mathrm{~b}$ & $17 \mathrm{a}$ & - \\
\hline F & & $45,0 * *$ & $98,4 * *$ & 11,1 \\
CV $(\%)$ & 12,3 & & - \\
\hline
\end{tabular}

'Médias seguidas de mesma letra não diferem significativamente entre si, pelo teste de Tukey a $5 \%$ de probabilidade.

Os resultados de fitotoxicidade podem ser vistos na Tabela 3. Observa-se que aos 7 DAT lactofen a $120 \mathrm{~g} / \mathrm{ha}$, aplicado isolado ou em mistura, propiciou os maiores sintomas (20\%), sendo superior aos demais tratamentos. Aos 14 DAT houve uma sensível redução dos sintomas onde a mistura de imazethapyr + chlorimuron-ethyl foi significativamente superior aos demais. Aos 30 DAT registrou-se ausência de fitotoxicidade para todos os tratamentos, mostrando que os herbicidas e misturas foram altamente seletivos para a cultura da soja.

\section{CONCLUSÕES}

Os resultados permitiram concluir que:

a. Lactofen aplicado de forma seqüencial a $60+60 \mathrm{~g} / \mathrm{ha}$ foi eficiente no controle de Euphorbía heterophylla, que apresenta resistência aos herbicidas inibidores de ALS.

b. Lactofen aplicado em dose única (120 g/ha) foi eficiente, mas inferior às misturas de lactofen com imazethapyr (120+ $\mathrm{g} / \mathrm{ha})$, chlorimuron-ethyl $(120+12,5 \mathrm{~g} / \mathrm{ha})$ e oxasulfuron $(120+45 \mathrm{~g} / \mathrm{ha})$.

c. As misturas de lactofen com imazethapyr, chlorimuronethyl e oxasulfuron foram eficientes no controle de biótipo de E. heterophylla com resistência aos herbicidas inibidores de ALS.

d. A mistura de lactofen com flumiclorac-pentil $(120+40 \mathrm{~g} /$ ha) apresentou bom controle de E. heterophylla.

e. Os herbicidas e as misturas, nas doses testadas, foram seletivos para a cultura da soja.

\section{LITERATURA CITADA}

EMBRAPA. Centro de Pesquisa Agropecuária do Oeste. Soja: recomendações técnicas para Mato Grosso do Sul e Mato Grosso. Dourados, 1996. 157p. (EMBRAPACPAO. Circular Técnica, 3).

GAZZIEIRO, D. L. P.; WOBETO, C.; CHRISTOFFOLETI, P.J. Resistência de plantas daninhas aos herbicidas. Londrina: EMBRAPA-CNPSO, 1998. (EMBRAPACNPSO. Folder, 6/98).

LORENZI, H. Manual de identificação e controle de plantas daninhas: plantio direto e convencional. 2ed. Nova Odessa: Ed. Autor, 1990. 220p.

MATHEWS, C.K., VAN HOLDE, K.E. Biochemistry. New York: Benjamin/Cummings, 1990. 1129 p.

PIMENTEL GOMES, F. A. A estatística moderna na pesquisa agropecuária. Piracicaba: POTAFOS, 1984. 160p.

PIMENTEL GOM ES, F. A. Estatística experimental. 11 ed. Piracicaba: Nobel, 1985. 466p.

RODRIGUES, B.N.; ALMEIDA, F.S. Guia de herbicidas. 4 ed. Londrina: Ed. dos Autores, 1998. 648p.

SOCIEDADE BRASILEIRA DA CIÊNCIA DAS PLANTAS DANINHAS. Procedimentos para instalação, avaliação e análise de experimentos com herbicidas. Londrina, 1995. 42p.

VIDAL, R. A. Herbicidas: mecanismos de ação e resistência de plantas. Porto Alegre: Ed. do Autor, 1997. 165p. 